\title{
MULTIPLE BUTTON-BALLS
}

\author{
R. W. Shupeld , Washington, $D C$.
}

$\mathrm{O}$ N PAGE 146 of the March, 1917, issue of American Forestry, I published a brief article on the "Sycamore or Buttonwood Tree Flower." It was illustrated by a cut showing that, in certain instances, there may be a short-peduncled flower-head or ball springing from one of the twigs of the tree, with another hanging below this, its peduncle being somewhat longer and apparently pressed into the upper ball at its proxi ral end. At the time this was published, I considered the condition rare, and so stated in $m y$ article. It caused many people to $100 \mathrm{k}$ up into the sycamores or plane trees, to ascertain if other specimens could be obtained. These were not long in coming. A specimen was sent me that had four balls to a string, the latter being formed by the peduncles in a straight line, the flower-heads or balls averaging about an inch apart. This specimen I published, with a brief account in the Journal of Heredity (July, 1917, p. 310), and this article brought me a good many more letters from correspondents who had observed similar strings of these flower-heads.

Then there was a lull in the correspondence which was rapidly showing me up as being a person who but rarely gazed heavenward-this at least being the case when I was either under or in the neighborhood of a plane tree. However this may be, the charge was to be brought home with still greater emphasis a little later on-indeed, it was not long on the way. The next surprise along this line of observation was handed me by Prof. Ralph L. Johnson, of Girard College, Philadelphia. During September, 1917, Professor Johnson sent down to me a box of buttonballs, whereon the united peduncles exhibited all the way from three to seven to a string. These balls were very large, dark colored, and furm, and they certainly presented a most remarkable sight. Many of them were over an inch in diameter; in some cases they were side by side on the common string, and in one or two instances there were three balls with peduncles so short that the group were mutually tangent to each other. I made a number of negatives of these interesting specimens, one of which is reproduced here to illustrate the present article.

Professor Johnson has kindly given me permission to publish his two very interesting letters on this subject, they being dated September 17, 1917, and September 25, 1917, respectively; they are reproduced in this order below.

\section{A TANDEM OF SEYEN}

Girard Coliege, Philadelphia, Pa. Sept. 17, 1917

Dr. R. W. SHUEELDT, SIR:

Washington, D. C.

After rcading your article in the Tuly Journal of Heredity, Vol. xviii, Page 310, I exnmined the sycamoro trees in Delaware Co., $\mathrm{Pa}$., and find tandems of four, five, six and one of seven button-balls.

Under separate rover I have sent you a tandem of four and of six respectively on tho same stem within three inches.

There is hanging in my study a spray with a peduncle with six balls, one of three, and two of four balls, all within seven inches upon the same branch. I have also a peduncle with seven button-balls; this I gathered from a sixfoot step ladder. On another branch within two inches there is a tandem of six and another of four balls. I have gathered three peduncles of five balls.

The tree is aboul eight inches in diameter and forty feet high. It perhaps came from the West Chester Nursery. It is growing beside a much used road, in the center of a suburb of West Philadelphia. There are wonderful clusters of button-balls on this tree, often a score upon a branch no thicher than a small pencil.

Kindly advise if you wish any further facts or service. I have not examined the tree minutely-only from a six-fnot ladder. There may be larger tandems than seven.

Yours most truly.

(Signed) Ralmil L. Johnson. 


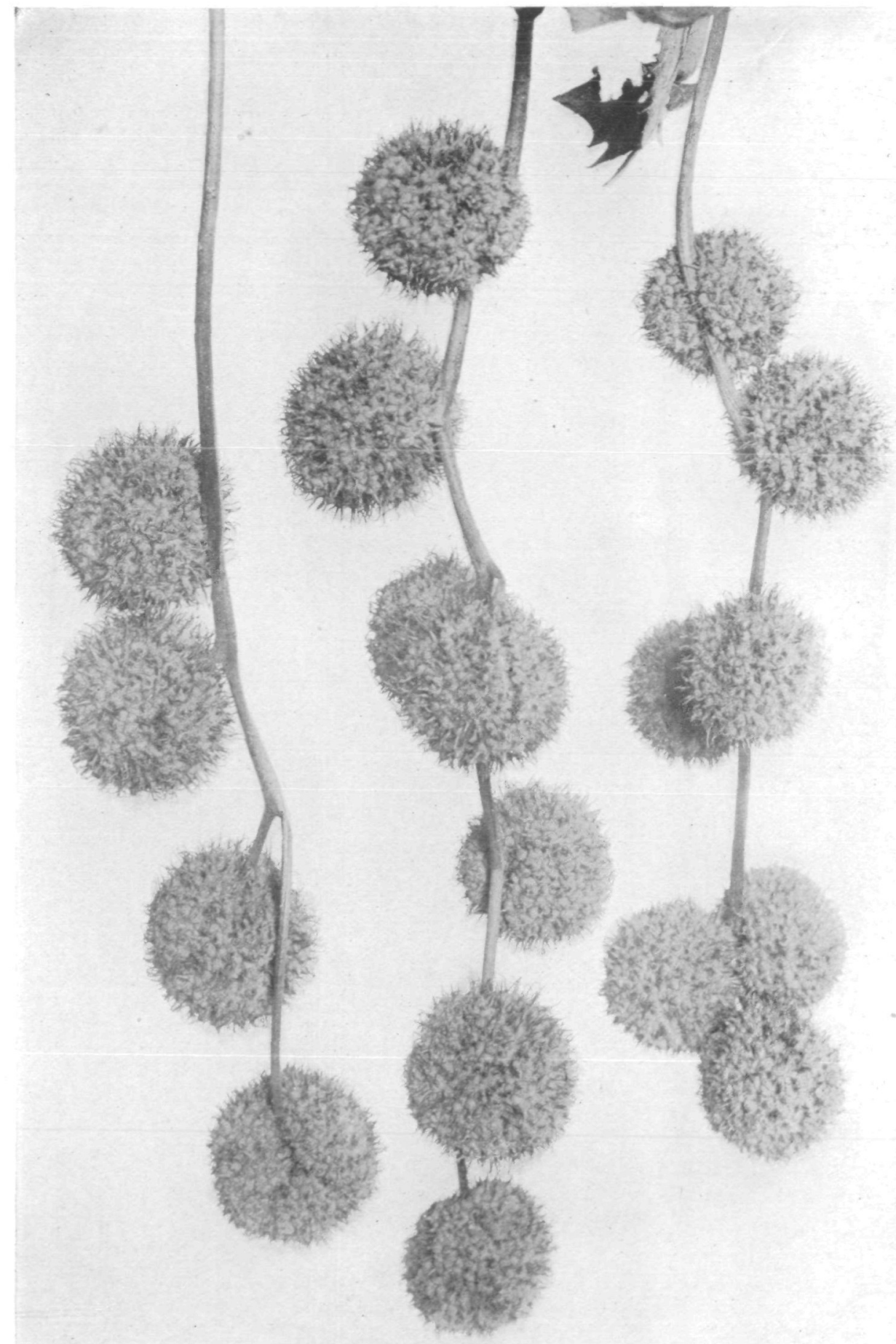

\section{SOME REMARKABLE STRINGS OF BUTTON-BALLS}

The sycamore Platanus occidentalis or, as it should be called, plane-tree in America usually bears single flower heads popularly called button-balls. Investigation by members of the American Genetic Association has brought to light strings of them containing as many as seven. Professor Augustine Henry, the distinguished British authority on trees, suggests that these trees may be hybrids between Plalanus occidentalis and P. acerifolia. Photograph (considerably reduced) by R. W. Shufeldt. (Fig. 6.) 


\author{
Girard College, \\ Philadelphia, Pa. \\ Sept. $25,1917$. \\ Dr. R. W. SHUFELDT, \\ 33.56 Fighteenth Street, \\ Washington, D. C. \\ DEAR SIR: \\ Your letter of Sept. 19th has caused me to \\ send by separate package a collection of \\ "tandems." Thest were selected Sept. 25, \\ 1917 , from the same tree described in my letter \\ of Sept. 17, 1917. \\ While there are many plane trees herc about, \\ I have not noticed the multiple balls on any \\ others. This tree, described in my former \\ letter, is so full of balls that from the ground \\ one is lead to believe that dozens are in a \\ cluster. \\ On a spray twelve inches long you will find \\ thirty balls arranged upon respective ped undes \\ as follows, proceeding toward the tip of the \\ branch: $3-3-5-5-4-5$; also within four inches
}

$4-7-5$ or a total of sixteen balls; then within seven inches on another $4-\overline{5}-5-6$; and again vithin the same distance $4-5-6-5$; then a peduncle with 4 balls beside onc with seven balls; a tandem of fire and a tandem of seven. This shows the balls grow odd and even to a respective peduncle.

Yours truly,

(Signed) RALPA L. JOHNSON.

I have requested Professor Johnson to obtain the history of this tree, if possible, and I trust he will succeed in doing so.

Should any reader of this article be so fortunate as to meet with a "tandem of eight balls," I would certainly like to hear of it. Seven on a string is the largest up to date.

\section{Babies Not Banished from Washington Apartment Houses}

Apartment houses are poor places in which to bring up children, but many children in large cities must be brought up in them, or not at all. The rule made by some apartment house managers, not to rent apartments to families with small children, is dangerous to eugenics, as encouraging childless families in a superior part of the population. It is therefore of importance to know how far such limitations are enforced.

The Journal of Heredity has investigated the policy of forty of the important houses of Washington. It is gratifying to find that thirty-nine of them do not object to children. As the demand for apartments in Washington greatly exceeds the supply, at the present time, an apartment house owner could hardly suffer any pecuniary loss if he discriminated against families with children, for there are plenty of childless families who would fill up his building. The fact that there is no discrimination against children cannot, therefore, be laid to a fear of losing money.

Only in one case, and that a relatively small apartment house, was it stated that families with small children would be barred. The manager explained that the same tenants had occupied the building for many years; that all of them were childless; and that the acci- dental presence of a uniformly childless set of tenants had led to his decision not to permit any intruders who would mar the harmony. The rule had recently been broken in one instance, he admitted, when a long-time tenant had violated the conventions by giving birth to offspring; but in view of the many years in which she and her husband had occupied the apartment he did not protest or evict them.

At this apartment house dogs were barred as well as babies. Of the whole list, twenty-nine apartment houses made no objection to dogs, if they were properly cared for; eleven refused to allow them.

Inquiry was made as to whether baby carriages were obliged to use the freight elevator. This was found uniformly to be the case, except in a few small buildings where there was no separate freight elevator.

Owners and lessees of apartment houses in the District of Columbia are to be congratulated on their attitude. It would be interesting to have similar investigations made in other cities, particularly in New York city, where it is commonly supposed that there has been much discrimination against babies on the part of real estate men. 